\title{
Alfabetización informacional en instituciones de educación superior: diseño de un instrumento de medición
}

\author{
María del Carmen Toledo Sánchez \\ Sonia Elizabeth Maldonado-Radillo \\ Universidad Autónoma de Baja California - UABC, México.
}

\section{ARTICLE}

\begin{abstract}
Resumen
Objetivo: Exponer los resultados de una fase investigativa psicométrica para demostrar la validez de un instrumento diseñado para medir la Alfabetización Informacional en las Instituciones de Educación Superior de México.

Método: El diseño del cuestionario de 50 ítems se fundamenta en los estándares UNESCO de competencias en tecnologías de información y comunicación (TIC) para docentes y en las normas sobre las aptitudes para el acceso y uso de la información en la enseñanza superior. La estrategia metodológica contempló los análisis de validez de contenido a través del Modelo de Lawshe, de correlación ítem-ítem y de constructo mediante el análisis factorial en una muestra fue de 73 docentes y bibliotecarios que laboran en instituciones educativas del noroeste de México.

Resultados: Los resultados revelan que el instrumento se redujo a 44 ítems y demostró que éstos evalúan el mismo constructo en una estructura interna que sugiere cinco dimensiones para la variable competencias informacionales y cuatro para competencias en TIC.

Conclusiones: Se concluye que los ítems tienen buena claridad en relación al concepto específico, no obstante, se precisó la eliminación de 6 ítems resultando válido y confiable como instrumento para medir la alfabetización informacional en el contexto estudiado.
\end{abstract}

Palabras clave

Alfabetizacion Informacional; Herramienta de medición; Validación; Instituciones de educación superior

Informational literacy in higher education: design of a mensuration tool

\begin{abstract}
Objective : To show psychometric research phase to examine the validity of an instrument designed to measure information literacy in the Institutions of higher education in Mexico.

Method: The questionnaire design of 50 items was based on the UNESCO standards of information and communication technologies (ICT) competencies for teachers and skills standards for access and use of information in higher education. The methodological strategy contemplated verification of content validity, item-item correlation and construct through factorial analysis. The sample was 73 professors and librarians who work in educational institutions of northwestern Mexico. Results: The final design was reduced to 44 items, and it demonstrated the items evaluate the same construct in their internal structure, and revealed 5 dimensions for informational variable competencies and 5 competencies for ICT.

Conclusions: The items have good clarity regarding the specific concept, nevertheless, the elimination of 6 items was needed proving to be a valid and reliable instrument to measure the informational literacy in the studied context.
\end{abstract}

Keywords

Information literacy; Mensuration tool; Validation; Higher education institutions 


\section{Introducción}

Durante muchos años se ha utilizado el término alfabetización para describir a las personas que desarrollaban sus habilidades de lectura, escritura y entendimiento; en la actualidad con los avances tecnológicos, se ha centrado el concepto como Alfabetización informacional (ALFIN), cuyo objetivo es capacitar a las personas "para buscar, evaluar, utilizar y crear información para lograr sus metas personales, sociales, ocupacionales y educativas" (párr. 1) que constituye un derecho humano básico en el mundo digital y promueve la inclusión social de todas las naciones (UNESCO, 2015).

Al abordar el tema de Alfabetización Informacional (ALFIN), se pueden encontrar diversos estudios que utilizan terminologías diferentes, como: Desarrollo de Habilidades Informativas (DHI) Alfabetización Informativa, Alfabetización en Información, Competencias en información, Competencias informativas, Formación de usuarios para la búsqueda de información, en el ámbito educativo cualquiera que se utilice es aceptable (Uribe, 2010).

Las Instituciones de Educación Superior (IES) en México realizan un gran esfuerzo para impulsar la alfabetización informacional (ALFIN), con el propósito de formar estudiantes competitivos que afronten con éxito a los retos tecnológicos y de información que se les presentan. En la actualidad las instituciones educativas, han incluido proyectos e implementación de ALFIN en sus programas educativos y bibliotecarios para afrontar el desarrollo tecnológico e impulsar a los usuarios de la información al uso adecuado de los recursos.

Los constantes cambios tecnológicos y la producción acelerada del flujo de información han motivado a las IES a exigir a los estudiantes y docentes un amplio conocimiento en el uso de tecnologías de información y comunicación (TIC), con la intención de desarrollar sus habilidades en el manejo de internet, documentos digitales, utilizar correctamente la información para generar conocimiento y participar en redes colaborativas de aprendizaje (Uribe, 2013).

Para responder a los retos que presenta la sociedad del conocimiento, los estudiantes deben de desarrollar la habilidad para usar de manera adecuada el flujo de la información, ya que es el principal recurso que poseen para mejorar la calidad educativa.

Es por ello que el tema de ALFIN juega un papel muy importante en la sociedad del conocimiento; es un pilar en las instituciones de educación educativa para lograr que las personas se preparen y puedan desarrollar competencias informativas para cumplir sus metas tanto laborales como educativas.

En la literatura reportan que se han realizado investigaciones respecto al tema de ALFIN, algunos estudios presentados como el de Lau y Cortes (2004), Sánchez (2008), Quindemil, (2010), Barbosa-Chacón et al. (2010). Cárdenas (2011), Cortes (2011), Bonilla (2013), Uribe-Tirado (2013), Barriga, et al (2014), han contribuido para implementar nuevos modelos de ALFIN, analizar competencias informacionales, elaborar normas y directrices de ALFIN en las instituciones educativas y bibliotecas.

A pesar que se han realizado numerosos estudios en cuestión de ALFIN a nivel internacional como nacional, en las IES falta profundizar respecto al tema (Uribe, 2010). Organismos como la UNESCO, The International Federation of Library Associations and Institution (IFLA) hacen esfuerzos para impulsar que las instituciones educativas desarrollen e incorporen programas ALFIN.

El objetivo de este estudio consiste identificar las propiedades psicométricas de un instrumento diseñado con el propósito de evaluar la Alfabetización Informacional en una muestra de docentes y bibliotecarios de instituciones de educación superior ubicadas en el noroeste de México, en cuanto a su contenido, estructura factorial y consistencia interna. Esto respondería la pregunta: ¿La estructura factorial del instrumento se ajusta al modelo propuesto?

La intención de este trabajo es que, a través de este instrumento, sea posible medir el grado de desarrollo de las habilidades informativas de los docentes y bibliotecarios de las instituciones de educación superior a través de sus competencias informacionales y competencias en tecnologías de la información y comunicación (TIC). El periodo de la investigación abarca de septiembre de 2014 a mayo de 2015.

Este estudio inicia abordando la importancia del tema que se pretende estudiar, la justificación, objetivo y contribución de la investigación, así como algunos fundamentos teóricos; posteriormente se describe la metodología empleada para el diseño del instrumento, y por último se exponen los resultados alcanzados durante el proceso de acumulación de evidencias de validez y confiabilidad del instrumento de alfabetización informacional. 


\section{Revisión de literatura}

Para mejorar la calidad educativa, en México existen organismos como los Comités Interinstitucionales para la Evaluación de la Educación Superior (CIEES), los cuales son organismos reconocidos por el Consejo para la Acreditación de la Educación Superior (COPAES) y el Centro Nacional para la Evaluación de la Educación Superior (CENEVAL), que se dedican a supervisar y respaldar los trabajos que realizan las IES para preservar la calidad y mejorar las competencias académicas (Tuirán, 2011).

Las competencias académicas promueven (1) el desarrollo de las capacidades humanas para tomar decisiones, (2) el trabajo en equipo, (3) la comunicación con otros individuos y (4) el uso de los avances tecnológicos, como las computadoras, para desempeñar sus actividades, con el propósito de aprender a aprender (Aguerrondo,2009). Hoy en día, las IES se preocupan por formar profesionales con competencias informacionales necesarias en la toma decisiones y para alcanzar ese objetivo deben contar con el capital humano, en este caso el personal docente y bibliotecario competentes para mejorar la calidad y eficiencia de sus programas formativos a través de conocer, consultar y evaluar la información que se precisa para la desarrollar habilidades informativas en los alumnos.

En la literatura se encuentran algunas investigaciones relacionados con ALFIN; López-Santana (2015) reporta un estudio en donde se hace una amplia descripción de los modelos existentes, en él se destaca que prestigiosas universidades de Australia y los Estados Unidos han incursionado en este tema desde la década de los 90 del siglo pasado. De la misma manera Quindemill (2010) realizó una revisión respecto al tema de ALFIN, indicando que estos países al igual que Gran Bretaña, llevan la delantera en la elaboración de modelos y normas, hecho que ha servido de base para que países como España y latinoamericanos adapten normas o construyan modelos de ALFIN dentro de sus programas institucionales. De acuerdo a su investigación en el Cuadro 1 se muestra la descripción general de los modelos que a consideración son los más destacados:

\section{Cuadro 1- Modelos de Alfabetización Informacional}

\begin{tabular}{|c|c|c|}
\hline Organización & Modelo & Descripción \\
\hline $\begin{array}{c}\text { Society of College National } \\
\text { and University (SCONUL). } \\
\text { (Gran Bretaña, 1999) }\end{array}$ & Seven Pillars Model. & $\begin{array}{l}\text { Este modelo muestra, a partir de siete pilares, las } \\
\text { relaciones entre el usuario de información } \\
\text { competente (nivel básico) y la idea más avanzada } \\
\text { de la competencia en aptitudes para el acceso y uso } \\
\text { de la información. }\end{array}$ \\
\hline $\begin{array}{l}\text { Association of College and } \\
\text { Research Libraries } \\
\text { ACRL/ALA } \\
\text { (USA) } \\
(2000)\end{array}$ & $\begin{array}{l}\text { Information Literacy } \\
\text { Competency Standards } \\
\text { for Higher Education. }\end{array}$ & $\begin{array}{l}\text { Las normas para alfabetización informacional en la } \\
\text { educación son cinco estándares o competencias a } \\
\text { alcanzar; cada uno tiene un grupo de indicadores y } \\
\text { resultados a medir. Permite su aplicación de forma } \\
\text { recurrente, exige que el alumno vuelva a una etapa } \\
\text { anterior del proceso, revise el planteamiento de } \\
\text { búsqueda de información y realice los mismos } \\
\text { pasos. }\end{array}$ \\
\hline $\begin{array}{c}\text { Council of Australian } \\
\text { University Librarians (CAUL) } \\
2000-2001\end{array}$ & Modelo CAUL & $\begin{array}{c}\text { Constituyen una adaptación de las Normas } \\
\text { ACRL/ALA, que emplearon el modelo relacional } \\
\text { (fenomenológico) de la ALFIN propuesto por Bruce. } \\
\text { Se diferencia de la norteamericana en la adición de } \\
\text { dos normas, para recoger en un total de 7, los } \\
\text { resultados y ejemplos para el desarrollo de } \\
\text { habilidades en información. }\end{array}$ \\
\hline$\frac{\text { Australian and New Zealand }}{\frac{\text { Institute for Information }}{2003}}$ & Modelo ANZIL & $\begin{array}{l}\text { Establece principios, normas y práctica, con una } \\
\text { redacción más precisa y directa de los indicadores } \\
\text { de rendimiento y resultados. Su contribución parte } \\
\text { de identificar la ALFIN como un elemento } \\
\text { fundamental para el aprendizaje continuo, y destaca } \\
\text { el trabajo en equipo para potenciar ese aprendizaje. }\end{array}$ \\
\hline $\begin{array}{c}\text { Tercer Encuentro sobre } \\
\text { Desarrollo de Habilidades } \\
\text { Informativas en el Contexto } \\
\text { Mexicano declaratoria de } \\
\text { Ciudad Juárez. } \\
\text { (2002) }\end{array}$ & $\begin{array}{c}\text { Normas sobre } \\
\text { Alfabetización } \\
\text { Informativa Educación } \\
\text { Superior }\end{array}$ & $\begin{array}{c}\text { Este es el único referente conocido con } \\
\text { trascendencia internacional generado en } \\
\text { Latinoamérica. Tiene presente los conocimientos } \\
\text { previos para la asimilación, evaluación y uso de la } \\
\text { información, además de incluir aspectos comunes } \\
\text { presentes en otros modelos y normas. }\end{array}$ \\
\hline
\end{tabular}

Fuente. Elaboración propia a partir del estudio de Quindemil (2010) 
En el ámbito cubano aparece la investigación de Avello-Martínez, López-Fernández, Cañedo-Iglesias, ÁlvarezAcosta, Granados-Romero, y Obando-Fraire (2013), quienes realizaron un estudio para conocer la evolución de ALFIN digital, realizando una revisión bibliográfica y teórica respecto al tema, encontrando que el desarrollo de la WEB 2.0 es el principal cambio de la conceptualización de Alfabetización digital. También Quindemil (2010), tiene una contribución importante al proponer la implementación de un modelo de competencias informacionales para que sea integrado al currículo en universidades cubanas específicamente en carrera de Bibliotecología y Ciencias de la Información, en el proceso evaluó los modelos existentes y afirmó que la implementación de un modelo de competencias informacionales potencializa el desarrollo informacional de los estudiantes.

En México, García (2007) llevó a cabo una investigación en comunidades de aprendizaje para de detectar el desarrollo de competencias en alfabetización informacional, a partir de la gestión del conocimiento, el diseño curricular, y el ambiente virtual de educación en línea. Este estudio posicionó a la Universidad de Guadalajara como la más avanzada, entre las universidades mexicanas, en la enseñanza virtual en formación de competencias.

No obstante las investigaciones encontradas aún falta por incursionar en el tema de ALFIN, sobre todo lo que refiere a instrumentos que miden el desarrollo de las habilidades informativas de los docentes, bibliotecarios e inclusive de los mismos alumnos.

Dado que la construcción de un instrumento de medida es una tarea compleja, después de definir el contexto de aplicación, se operacionalizaron las variables de medida: Competencias informacionales y Competencias en tecnologías de la información y comunicación.

La variable competencias informacionales se diseñó considerando las normas sobre las aptitudes para el acceso y uso de la información en la enseñanza superior (ACRL, 2000); incluye cuatro dimensiones: 1) Capacidad para determinar la información, 2) Acceso a la información, 3) Evaluación de la información y 4) Utilización de la información. Esta variable alude a la habilidad de pensar de manera crítica e integrada acerca de las necesidades de información y el conocimiento sobre cómo encontrar, evaluar la calidad, usar y gestionar, la información que se necesita (Goetsch, et al., 1998).

Para construir la variable competencias en tecnologías de la información y comunicación (TIC), se tomaron los estándares UNESCO de competencias en TIC para docentes (UNESCO, 2008); esta variable es entendida como la habilidad para elegir la tecnología que se utiliza para crear, almacenar, intercambiar y procesar información a través de conversaciones, voz, imágenes, presentaciones multimedia que se relacionan con las computadoras, software y telecomunicaciones (Tello, 2008). Esta variable incluye las dimensiones: 1) Nociones básicas, 2) Profundización del conocimiento y 3) TIC para la generación del conocimiento.

\section{Metodología}

Esta investigación tiene un enfoque cuantitativo, es aplicada y su estrategia metodológica se basó en un estudio descriptivo con diseño no experimental. Se llevó a cabo en dos etapas: la Etapa 1 corresponde a la construcción de los ítems, en ella se establecieron las definiciones operativas de las variables de medida y las directrices para la elaboración de ítems de elección múltiple; mientras que en la Etapa 2 se realizó el estudio piloto cualitativo y cuantitativo en donde se analizó, depuró y se ajustó la nueva versión del instrumento.

\subsection{Muestreo por conveniencia.}

En este estudio participaron docentes y bibliotecarios de todas las instituciones de educación superior ubicadas en el estado de Baja California, México, logrando recopilar 73 cuestionarios de acuerdo a la disponibilidad de los respondientes. El $65.75 \%$ de los encuestados laboran en universidad autónoma, el 12.3\% en tecnológicos, el $10.96 \%$ en universidades pedagógicas, $1.37 \%$ en universidad tecnológica y resto en otras instituciones.

\subsection{Diseño del instrumento.}

Se elaboró un cuestionario que asegurara la validez del concepto Alfabetización Informacional; para lograrlo, se tomaron en consideración: las normas sobre las aptitudes para el acceso y uso de la información en la enseñanza superior (ACRL, 2000 y los estándares UNESCO de competencias en TIC para docentes (UNESCO, 2008). El instrumento en su versión original se integró por 50 ítems; su escalamiento fue de tipo Likert, donde (1) nunca, (2) rara vez, (3) ocasionalmente, (4) frecuentemente, y (5) muy frecuentemente. La puntuación mínima 
para los ítems fue de 1 y la máxima de 5.

La reproducibilidad, utilidad y validez son requisitos indispensables que debe cumplir cualquier instrumento de medición (Lamprea y Gómez-Restrepo, 2007) para que éste sea válido y confiable. La validez indica la capacidad del instrumento para medir el constructo que se pretende cuantificar; se refiere al "grado de confianza que se tiene de que la medición corresponde a la realidad del fenómeno que se está midiendo" (Lamprea y Gómez-Restrepo, 2007:342). La validez da respuesta a la pregunta ¿con qué fidelidad responde la población (o muestra) al atributo que se va a medir? En este trabajo, la validez del instrumento se analizó de tres formas: (1) validez de contenido, (2) Validez discriminante y (3) validez de constructo.

\subsection{Validez del instrumento}

\subsubsection{Validez de contenido}

La validez de contenido, se define como el "grado en que un instrumento refleja un dominio específico de contenido de lo que se mide” (Hernández-Sampieri, et al., 2010, pp. 201) es decir la validez de contenido mide el valor del concepto.

A fin de establecer la validez de contenido de un instrumento, se tomó el modelo de Lawshe (1975) modificado por Tristán-López (2008) que corrige los problemas de Lawshe y es más fácil de interpretar; para llevar a cabo este proceso se trabajó con 7 jueces o expertos en el área. 5 académicos con grado de doctorado que pertenecen a la Universidad Autónoma de Baja California, 1 académico con grado de doctorado que pertenece a la Universidad Autónoma de Ciudad Juárez y 1 académico estudiante de posdoctorado en la Universidad de la Rioja España. A ellos se les pidió que evaluaran por separado los ítems del cuestionario de acuerdo a su relevancia definida como la importancia del ítem para la evaluación de la Calidad del servicio, con base en la siguiente escala: 1) Esencial, 2) Útil pero no esencial, y 3) No importante. La información recabada de los expertos se analizó a través de una hoja de cálculo de Microsoft Excel 2010 @ y se determinó la razón de validez de contenido (CVR y CVR') para cada uno de los ítems mediante las ecuaciones descritas en el Modelo de Lawshe modificado (Tristán-López, 2008) y el Índice de Validez de Contenido (CVI) para el instrumento global.

\subsubsection{Validez discriminante}

Se utilizó con la intención de identificar los grupos de ítems que miden rasgos diferentes que son consistentes con el grupo pero que no se relacionan con otros ítems (Céspedes, 2012). Esta validez se determinó empleando la prueba de correlación punto-biserial o ítem total. Según Morales (2007) el análisis de ítem se puede verificar si las personas que respondieron el cuestionario comprendieron el significado de cada pregunta, de lo contrario se deberá eliminar la pregunta o reformularla.

\subsubsection{Validez de constructo}

La validez de constructo "es el grado en que una medición se relaciona de manera consistente con otras mediciones" (Hernández-Sampieri et al., 2010, p.349), lo que se pretende al realizar la validez de este tipo, es explorar la estructura interna del instrumento, su dimensionalidad (Carretero-Dios y Pérez, 2005).Para determinar la construcción lógica del instrumento, en primer término, se recurrió al análisis factorial exploratorio (AFE), en la extracción de factores se empleó el método de componentes principales aplicando rotación ortogonal Varimax, el cual permite una separación más clara de las variables, al maximizar las correlaciones entre los ítems y sus dominios. Previo se verificó la adecuación de los datos mediante dos indicadores del grado de asociación de las variables como son las pruebas de Kaiser-Meyer-Olkin (KMO) y de esfericidad de Barlett (Lévy y Varela, 2003).

\subsubsection{Fiabilidad del instrumento}

De acuerdo a la teórica clásica, mencionada por Oviedo y Campo-Arias (2005) la fiabilidad es el grado que un instrumento tiene consistencia con varios de los ítem que mide. En esta investigación la fiabilidad determinó a través del alfa de Cronbach con la intención de establecer la medida en la cual el constructo que se pretende medir está presente en cada uno de los ítems y el grado en que éstos pertenecientes a una escala se correlacionan entre sí (Campo-Arias y Oviedo, 2008; Carretero-Dios y Pérez, 2005). 


\section{Resultados}

\subsection{Validez de contenido}

Para establecer la validez de los ítems, se empleó el método Lawshe (1975), en el que participaron 7 expertos para emitir su opinión, se les pidió que evaluaran cada ítem de acuerdo a su relevancia, considerando 1. Esencial, 2. Útil/No esencial y 3. No importante. Los resultados de frecuencia emitidos por los expertos se muestran en la Tabla 2.

Tabla 2. Validez de contenido - Modelo Lawshe

\begin{tabular}{|c|c|c|c|c|c|c|c|c|}
\hline Variable & Dimensión & Indicador & Ítem & Esencial & $\begin{array}{l}\text { Útil/ No } \\
\text { esencial }\end{array}$ & $\begin{array}{c}\text { No } \\
\text { importante }\end{array}$ & CVR & CVR' $^{\prime}$ \\
\hline \multirow{16}{*}{ 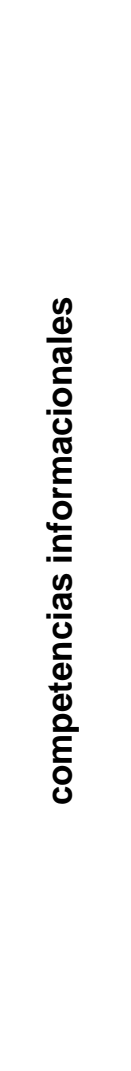 } & \multirow{7}{*}{$\begin{array}{c}\text { Capacidad } \\
\text { para } \\
\text { determinar } \\
\text { la } \\
\text { información }\end{array}$} & $\begin{array}{l}\text { Necesidad } \\
\text { informativa }\end{array}$ & 22 & 5 & 0 & 2 & 0.429 & 0.7143 \\
\hline & & \multirow{4}{*}{$\begin{array}{l}\text { Identificación de } \\
\text { recursos } \\
\text { informativos }\end{array}$} & 23 & 7 & 0 & 0 & 1.000 & 1.000 \\
\hline & & & 24 & 5 & 2 & 0 & 0.429 & 0.714 \\
\hline & & & 25 & 6 & 1 & 0 & 0.714 & 0.857 \\
\hline & & & 26 & 6 & 1 & 0 & 0.714 & 0.857 \\
\hline & & \multirow{2}{*}{$\begin{array}{l}\text { Búsqueda de } \\
\text { medios para } \\
\text { localizar la } \\
\text { información }\end{array}$} & 27 & 5 & 2 & 0 & 0.429 & 0.714 \\
\hline & & & 28 & 5 & 2 & 0 & 0.429 & 0.714 \\
\hline & \multirow{9}{*}{$\begin{array}{l}\text { Acceso a la } \\
\text { información }\end{array}$} & \multirow{2}{*}{$\begin{array}{l}\text { Reconocimiento } \\
\text { de estrategias de } \\
\text { búsqueda }\end{array}$} & 29 & 5 & 1 & 1 & 0.429 & 0.714 \\
\hline & & & 30 & 6 & 1 & 0 & 0.714 & 0.857 \\
\hline & & \multirow{2}{*}{$\begin{array}{l}\text { Facilidad en } \\
\text { manejar los } \\
\text { métodos de } \\
\text { búsqueda }\end{array}$} & 31 & 6 & 1 & 0 & 0.714 & 0.857 \\
\hline & & & 32 & 6 & 0 & 1 & 0.714 & 0.857 \\
\hline & & $\begin{array}{l}\text { Iniciativa para } \\
\text { consultar a } \\
\text { expertos } \\
\text { referente al tema } \\
\text { de búsqueda de } \\
\text { información } \\
\end{array}$ & 33 & 5 & 2 & 0 & 0.429 & 0.714 \\
\hline & & \multirow{4}{*}{$\begin{array}{l}\text { Facilidad para } \\
\text { manejar las } \\
\text { herramientas } \\
\text { tecnológicas en } \\
\text { el acceso a la } \\
\text { información }\end{array}$} & 35 & 6 & 1 & 0 & 0.714 & 0.857 \\
\hline & & & 36 & 4 & 3 & 0 & 0.143 & 0.571 \\
\hline & & & 37 & 5 & 0 & 2 & 0.429 & 0.714 \\
\hline & & & 38 & 2 & 1 & 4 & $0 . \overline{429}$ & 0.285 \\
\hline \multirow{12}{*}{ 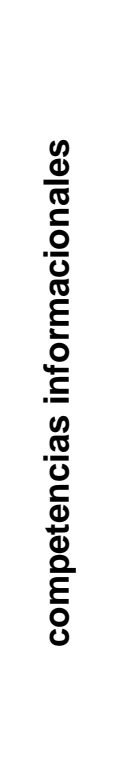 } & \multirow{7}{*}{$\begin{array}{c}\text { Evaluación } \\
\text { de } \\
\text { información }\end{array}$} & $\begin{array}{l}\text { Contenido de } \\
\text { información }\end{array}$ & $\begin{array}{l}39 \\
40\end{array}$ & $\begin{array}{l}7 \\
7\end{array}$ & 0 & 0 & $\begin{array}{l}1.000 \\
1.000\end{array}$ & $\begin{array}{l}1.000 \\
1.000\end{array}$ \\
\hline & & \multirow{4}{*}{$\begin{array}{l}\text { Comparación de } \\
\text { información para } \\
\text { evaluar su uso }\end{array}$} & 41 & 5 & 2 & 0 & 0.429 & 0.714 \\
\hline & & & 42 & 6 & 1 & 0 & 0.714 & 0.857 \\
\hline & & & 43 & 3 & 3 & 1 & $0 . \overline{143}$ & 0.429 \\
\hline & & & 44 & 5 & 1 & 1 & 0.429 & 0.714 \\
\hline & & \multirow{2}{*}{$\begin{array}{l}\text { Evaluación de las } \\
\text { fuentes de } \\
\text { información }\end{array}$} & 45 & 6 & 1 & 0 & 0.714 & 0.857 \\
\hline & & & 46 & 6 & 0 & 1 & 0.714 & 0.857 \\
\hline & \multirow{5}{*}{$\begin{array}{l}\text { Utilización } \\
\text { de } \\
\text { información }\end{array}$} & \multirow{2}{*}{$\begin{array}{l}\text { Organización de } \\
\text { la información } \\
\text { recuperada }\end{array}$} & 47 & 6 & 1 & 0 & 0.714 & 0.857 \\
\hline & & & 48 & 7 & 0 & 0 & 1.000 & 1.000 \\
\hline & & \multirow{3}{*}{$\begin{array}{l}\text { Comunicar } \\
\text { eficazmente la } \\
\text { información. }\end{array}$} & 49 & 6 & 1 & 0 & 0.714 & 0.857 \\
\hline & & & 50 & 6 & 1 & 0 & 0.714 & 0.857 \\
\hline & & & 51 & 6 & 1 & 0 & 0.714 & 0.857 \\
\hline
\end{tabular}


Tabla 2. Validez de contenido Modelo Lawshe (Continuación)

\begin{tabular}{|c|c|c|c|c|c|c|c|c|}
\hline Variable & Dimensión & Indicador & Ítem & Esencial & $\begin{array}{l}\text { Útil/ No } \\
\text { esencial }\end{array}$ & $\begin{array}{c}\text { No } \\
\text { importante }\end{array}$ & CVR & CVR' \\
\hline \multirow{5}{*}{ 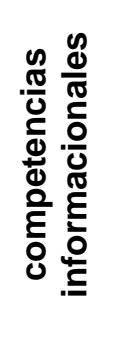 } & \multirow{5}{*}{$\begin{array}{c}\text { Utilización } \\
\text { de } \\
\text { información }\end{array}$} & \multirow{2}{*}{$\begin{array}{l}\text { Organización de } \\
\text { la información } \\
\text { recuperada }\end{array}$} & 47 & 6 & 1 & 0 & 0.714 & 0.857 \\
\hline & & & 48 & 7 & 0 & 0 & 1.000 & 1.000 \\
\hline & & \multirow{3}{*}{$\begin{array}{l}\text { Comunicar } \\
\text { eficazmente la } \\
\text { información. }\end{array}$} & 49 & 6 & 1 & 0 & 0.714 & 0.857 \\
\hline & & & 50 & 6 & 1 & 0 & 0.714 & 0.857 \\
\hline & & & 51 & 6 & 1 & 0 & 0.714 & 0.857 \\
\hline \multirow{22}{*}{ 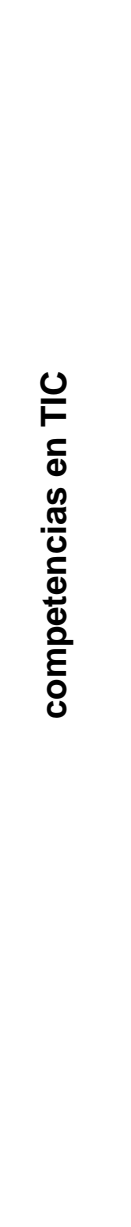 } & \multirow{10}{*}{$\begin{array}{l}\text { Nociones } \\
\text { básicas }\end{array}$} & \multirow{4}{*}{$\begin{array}{l}\text { Uso de } \\
\text { recursos } \\
\text { tecnológicos }\end{array}$} & 52 & 6 & 0 & 1 & 0.714 & 0.857 \\
\hline & & & 53 & 6 & 1 & 0 & 0.714 & 0.857 \\
\hline & & & 54 & 5 & 2 & 0 & 0.429 & 0.714 \\
\hline & & & 55 & 7 & 0 & 0 & 1.000 & 1.000 \\
\hline & & \multirow{2}{*}{$\begin{array}{l}\text { Uso e } \\
\text { aplicaciones } \\
\text { informáticas }\end{array}$} & 56 & 4 & 2 & 1 & 0.143 & 0.571 \\
\hline & & & 57 & 6 & 1 & 0 & 0.714 & 0.857 \\
\hline & & \multirow{4}{*}{$\begin{array}{l}\text { Utilización de } \\
\text { herramientas } \\
\text { informáticas } \\
\text { virtuales }\end{array}$} & 58 & 5 & 2 & 0 & 0.429 & 0.714 \\
\hline & & & 59 & 7 & 0 & 0 & 1.000 & 1.000 \\
\hline & & & 60 & 5 & 1 & 1 & 0.429 & 0.714 \\
\hline & & & 61 & 6 & 1 & & 0.714 & 0.857 \\
\hline & \multirow{5}{*}{$\begin{array}{c}\text { Profundización } \\
\text { del } \\
\text { conocimiento }\end{array}$} & \multirow{2}{*}{$\begin{array}{l}\text { Facilidad de } \\
\text { acceso a los } \\
\text { recursos } \\
\text { tecnológicos }\end{array}$} & 62 & 5 & 2 & 0 & 0.429 & 0.714 \\
\hline & & & 63 & 7 & 0 & 0 & 1.000 & 1.000 \\
\hline & & \multirow{3}{*}{$\begin{array}{l}\text { Uso de } \\
\text { aplicaciones } \\
\text { informáticas y } \\
\text { tecnológicas }\end{array}$} & 64 & 5 & 2 & 0 & 0.429 & 0.714 \\
\hline & & & 65 & 7 & 0 & 0 & 1.000 & 1.000 \\
\hline & & & 66 & 7 & 0 & 0 & 1.000 & 1.000 \\
\hline & \multirow{7}{*}{$\begin{array}{c}\text { TIC para } \\
\text { Generación de } \\
\text { conocimiento }\end{array}$} & \multirow{3}{*}{$\begin{array}{l}\text { Organización } \\
\text { de recursos } \\
\text { tecnológicos }\end{array}$} & 67 & 6 & 1 & 0 & 0.714 & 0.857 \\
\hline & & & 68 & 6 & 0 & 1 & 0.714 & 0.857 \\
\hline & & & 69 & 5 & 1 & 1 & 0.429 & 0.714 \\
\hline & & \multirow{2}{*}{$\begin{array}{l}\text { Elaborar } \\
\text { proyectos } \\
\text { utilizando los } \\
\text { recursos y } \\
\text { herramientas } \\
\text { informáticas }\end{array}$} & 70 & 5 & 2 & 0 & 0.429 & 0.714 \\
\hline & & & 71 & 5 & 1 & 1 & 0.429 & 0.714 \\
\hline & & \multirow[b]{2}{*}{ Total ítems } & & & & $\mathrm{S}=$ & 30.00 & 40.00 \\
\hline & & & 50 & \multicolumn{2}{|c|}{$\begin{array}{r}\text { Todos } \\
\text { Solo aceptables }\end{array}$} & $\begin{array}{l}\mathrm{CVI}= \\
\mathrm{CVI}=\end{array}$ & $\begin{array}{l}.652 \\
.658\end{array}$ & $\begin{array}{l}.870 \\
.829\end{array}$ \\
\hline
\end{tabular}

Fuente: Elaboración propia: utilizando las ecuaciones de Lawshe (1975) y Tristán (2008).

La mayoría de los ítems tienen un CVR' elevado, así mismo los ítems 23, 39, 40, 48, 55, 59, 63, 65, 66 alcanzaron la puntuación más alta (1.00), mientras que los ítem 36, 38, 43,56 tienen una puntuación por debajo del valor aceptables (0.582) considerados por los jueces como no importantes.

La validez de contenido global (CVI) calculada de acuerdo al modelo de Lawshe es de 0.829, esto significa que la evaluación realizada por los expertos considera fundamental el concepto de alfabetización informacional.

De acuerdo al resultado del CVR, se sugiere la depuración de 4 ítems del cuestionario original, eliminado los ítems 36, 38, 43, 56, por estar con un valor menor a 0.582, quedando el instrumento compuesto por 46 ítems.

En la tabla 3 se observar que el 92\% de los ítems se consideran aceptables por tener un CVR' mayor a 0.582. 
Tabla 3. Resultado de Validez de contenido

\begin{tabular}{c|cc}
\hline & $\begin{array}{c}\text { Aceptables } \\
\text { ítem >=.582 }\end{array}$ & $\begin{array}{c}\text { No aceptables } \\
\text { ítem <=.582 }\end{array}$ \\
\hline $\begin{array}{c}\text { total de ítem } \\
\text { valorados } \\
\text { Porcentaje }\end{array}$ & 46 & 4 \\
\hline \multicolumn{2}{c}{ Fuente: Elaboración propia } \\
\hline \multicolumn{2}{c}{}
\end{tabular}

\subsection{Validez discriminante}

En el análisis de ítem se calculó con el índice de discriminación (homogeneidad) a través de la correlación total de elementos corregida, encontrando una correlación mínima con los demás ítem de 0.276 y la máxima de 0.748 (Tabla 4).

Tabla 4. Análisis de ítem

\begin{tabular}{|c|c|c|c|}
\hline Variable & Ítem & $\begin{array}{c}\text { Correlación } \\
\text { total } \\
\text { corregida }\end{array}$ & $\begin{array}{c}\text { Alfa de } \\
\text { Cronbach s } \\
\text { el elemento } \\
\text { se ha } \\
\text { suprimido }\end{array}$ \\
\hline 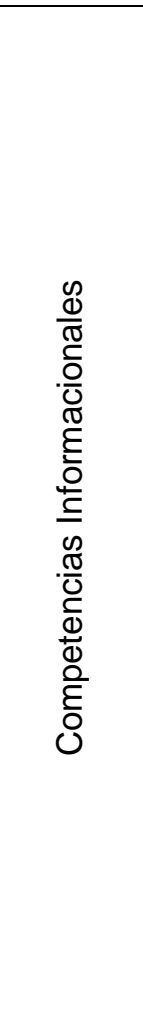 & $\begin{array}{l}22 \text { (CDI) } \\
23 \text { (CDI) } \\
24 \text { (CDI) } \\
25 \text { (CDI) } \\
26 \text { (CDI } \\
27 \text { (CDI)) } \\
28 \text { (CDI) } \\
29 \text { (CAI) } \\
30 \text { (CAI) } \\
31 \text { (CAI) } \\
32 \text { (CAI) } \\
33 \text { (CAI) } \\
34 \text { (CAI) } \\
35 \text { (CAI) } \\
37 \text { (CAI) } \\
39 \text { (CEI } \\
40 \text { (CEI) } \\
41 \text { (CEI) } \\
42 \text { (CEI) } \\
44 \text { (CEI) } \\
45 \text { (CEI) } \\
46 \text { (CEI) } \\
47 \text { (CUI) } \\
48 \text { (CUI). } \\
49 \text { (CUI) } \\
50 \text { (CUI) }\end{array}$ & $\begin{array}{l}.490 \\
.548 \\
.404 \\
.682 \\
.572 \\
.537 \\
.418 \\
.583 \\
.358 \\
.604 \\
.663 \\
.421 \\
.726 \\
.276 \\
.714 \\
.721 \\
.657 \\
.356 \\
.552 \\
.512 \\
.614 \\
.534 \\
.431 \\
.748 \\
.559 \\
.567\end{array}$ & $\begin{array}{l}.950 \\
.950 \\
.950 \\
.949 \\
.950 \\
.950 \\
.950 \\
.950 \\
.951 \\
.949 \\
.949 \\
.950 \\
.949 \\
.951 \\
.948 \\
.949 \\
.949 \\
.951 \\
.950 \\
.950 \\
.949 \\
.950 \\
.950 \\
.949 \\
.949 \\
.950\end{array}$ \\
\hline
\end{tabular}

Fuente: Elaboración propia 
Tabla 4. Análisis de ítem (Continuación)

\begin{tabular}{l|l|c|c}
\hline Variable & Ítem & $\begin{array}{c}\text { Correlación } \\
\text { total } \\
\text { corregida }\end{array}$ & $\begin{array}{c}\text { Alfa de } \\
\text { Cronbach si } \\
\text { el elemento } \\
\text { se ha } \\
\text { suprimido }\end{array}$ \\
\hline & 51 (CUI) & .404 & .950 \\
& 52 (TNB) & .553 & .950 \\
53 (TNB) & .497 & .950 \\
54 (TNB) & .388 & .951 \\
55 (TNB) & .569 & .950 \\
57 (TNB) & .236 & .951 \\
58 (TNB) & .552 & .950 \\
& 59 (TNB) & .723 & .948 \\
60 (TNB) & .662 & .949 \\
61 (TNB) & .627 & .949 \\
62 (TPC) & .553 & .950 \\
63 (TPC) & .668 & .949 \\
64 (TPC) & .538 & .950 \\
65 (TPC) & .642 & .949 \\
66 (TPC) & .610 & .949 \\
67 (TGC) & .591 & .950 \\
68 (TGC) & .341 & .951 \\
69 (TGC) & .643 & .949 \\
70 (TGC) & .360 & .951 \\
71 (TGC) & .598 & .949 \\
\hline
\end{tabular}

Fuente: Elaboración propia

Para el ítem 35 tiene una correlación total baja de 0.276 y el ítem 57 con una puntuación de 0.236, por lo que se sugiere que deberían ser eliminados por estar por debajo del mínimo (0.30) (Gil, 2011).En el caso de tomar la decisión de eliminar los ítems 35 y 57 se debe considerar que no afectará el alfa de Cronbach ya que continuaría en 0.951 .

Con fundamento en el análisis de ítem se eliminaron los ítems 35 y 57 que tienen una baja correlación, quedando el instrumento compuesto en su versión final por 44 ítems (Tabla 5).

Tabla 5. Depuración de la escala de medición

\begin{tabular}{|c|c|c|c|c|c|}
\hline Variable & Dimensión & $\begin{array}{l}\text { Después } \\
\text { del AC }\end{array}$ & Total & $\begin{array}{c}\text { Después } \\
\text { del Al }\end{array}$ & $\begin{array}{l}\text { Total de } \\
\text { ítems }\end{array}$ \\
\hline \multirow{4}{*}{ 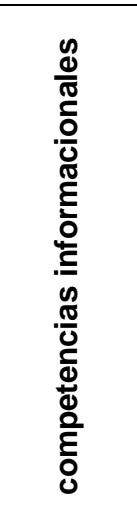 } & $\begin{array}{l}\text { Capacidad para } \\
\text { determinar la } \\
\text { información }\end{array}$ & $\begin{array}{c}22 \\
23,24,25,26 \\
27,28 \\
\end{array}$ & 7 & $\begin{array}{c}22 \\
23,24,25, \\
26 \\
27,28 \\
\end{array}$ & 7 \\
\hline & $\begin{array}{l}\text { Acceso a la } \\
\text { información }\end{array}$ & $\begin{array}{l}29,30 \\
31,32 \\
33,34 \\
35,37 \\
\end{array}$ & 8 & $\begin{array}{c}29,30 \\
31,32 \\
33,34 \\
37 \\
\end{array}$ & 7 \\
\hline & $\begin{array}{l}\text { Evaluación de } \\
\text { información }\end{array}$ & $\begin{array}{c}39,40 \\
41,42,44 \\
45,46 \\
\end{array}$ & 7 & $\begin{array}{c}39,40 \\
41,42,44 \\
45,46\end{array}$ & 7 \\
\hline & $\begin{array}{l}\text { Utilización de } \\
\text { información }\end{array}$ & $\begin{array}{c}47,48 \\
49,50,51\end{array}$ & 5 & $\begin{array}{c}47,48 \\
49,50,51\end{array}$ & 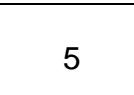 \\
\hline
\end{tabular}


Tabla 5. Depuración de la escala de medición (Continuación)

\begin{tabular}{|c|c|c|c|c|c|}
\hline Variable & Dimensión & $\begin{array}{l}\text { Después } \\
\text { del AC }\end{array}$ & Total & $\begin{array}{l}\text { Después } \\
\text { del Al }\end{array}$ & $\begin{array}{l}\text { Total de } \\
\text { ítems }\end{array}$ \\
\hline \multirow{6}{*}{ 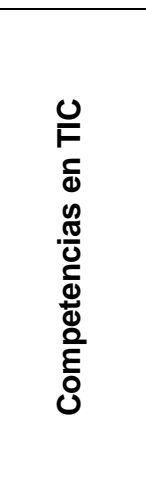 } & \multirow{3}{*}{ Nociones básicas } & $52,53,54,55$ & & $\begin{array}{l}52,53,54, \\
55\end{array}$ & \multirow{3}{*}{8} \\
\hline & & 57 & 9 & & \\
\hline & & $58,59,60,61$ & & $\begin{array}{c}58,59,60 \\
61\end{array}$ & \\
\hline & $\begin{array}{l}\text { Profundización del } \\
\text { conocimiento }\end{array}$ & $\begin{array}{c}62,63 \\
64,65,66\end{array}$ & 5 & $\begin{array}{c}62,63 \\
64,65,66\end{array}$ & 5 \\
\hline & $\begin{array}{l}\text { TIC para Generación } \\
\text { de conocimiento }\end{array}$ & $\begin{array}{l}67,68,69 \\
\quad 70,71\end{array}$ & 5 & $\begin{array}{l}67,68,69 \\
\quad 70,71\end{array}$ & 5 \\
\hline & Total de İtem & & 46 & & 44 \\
\hline
\end{tabular}

Fuente: Elaboración propia

\subsection{Validez de Constructo}

Como se mencionó la validez de constructo fue evaluada mediante el análisis factorial, primeramente se determinó el KMO y la prueba de Barlett con la intención de conocer si la adecuación de la muestra tiene correlación suficiente entre las variables. Los resultados de la prueba de KMO para la variable competencias informacionales es de 0.806 y una significancia en la prueba de esfericidad de Bartlett 0.000 , y para la variable competencias en TIC la prueba de KMO es de 0.824 con una significancia en la prueba de esfericidad de Bartlett 0.000, representa que los datos son adecuados para usar el análisis factorial (Pérez, 2009). En el primer análisis factorial arrojó una variación explicada de $75.617 \%$; sin embargo, no fue posible obtener una matriz rotada por razón de la no convergencia en 25 iteracciones, por lo que se sugiere realizar una segunda solución factorial para cada variable.

\subsection{Variable competencias informacionales}

El análisis de componentes principales identificó cinco componentes con autovalores varían de 1.214 a 10.305; el primer componente explica el mayor porcentaje de variabilidad de los datos con $16.378 \%$, en tanto que los cinco componentes sumados explican el $66.766 \%$ de la variabilidad (Tabla 6). La rotación ortogonal (Varimax) de la matriz de componentes ha agrupado los 26 ítems en cinco factores independientes. Los factores (componentes) 1, 2 y 3 agrupan 6 ítems cada uno; el factor 4 se integra por 5 ítems y el factor 5 por solo 3 ítems.

Tabla 6. Varianza explicada para la variable Competencias informacionales

\begin{tabular}{|c|c|c|c|c|c|c|c|c|c|}
\hline \multirow[t]{2}{*}{ Componente } & \multicolumn{3}{|c|}{ Autovalores iniciales } & \multicolumn{3}{|c|}{$\begin{array}{c}\text { Sumas de extracción de cargas } \\
\text { al cuadrado }\end{array}$} & \multicolumn{3}{|c|}{$\begin{array}{c}\text { Sumas de rotación de cargas al } \\
\text { cuadrado }\end{array}$} \\
\hline & Total & $\begin{array}{c}\% \text { de } \\
\text { varianza }\end{array}$ & $\begin{array}{c}\% \\
\text { acumulado }\end{array}$ & Total & $\begin{array}{c}\% \text { de } \\
\text { varianza }\end{array}$ & $\begin{array}{c}\% \\
\text { acumulado }\end{array}$ & Total & $\begin{array}{c}\% \text { de } \\
\text { varianza }\end{array}$ & $\begin{array}{c}\% \\
\text { acumulado }\end{array}$ \\
\hline 1 & 10.305 & 39.634 & 39.634 & 10.305 & 39.634 & 39.634 & 4.258 & 16.378 & 16.378 \\
\hline 2 & 2.625 & 10.098 & 49.7 & 2.625 & 10.098 & 49. & 3.900 & 15.000 & 31. \\
\hline 3 & 1.690 & 6.500 & 56.232 & 1.690 & 6.500 & 56.232 & 3.298 & 12.683 & 44 \\
\hline 4 & 1.524 & 5.863 & 62.095 & 1.524 & 5.863 & 62.0 & 3.252 & 12.508 & 56.569 \\
\hline 5 & 1.214 & 4.671 & 66.766 & 1.214 & 4.671 & 66.766 & 2.651 & 10.198 & 66.766 \\
\hline 6 & 1.090 & 4.192 & 70.958 & & & & & & \\
\hline
\end{tabular}

Fuente: Elaboración propia, a partir del método de extracción: análisis de componentes principales.

En la Tabla 6a se muestran las cargas factoriales correspondientes a los ítems de cada factor; como se observa en su gran mayoría son altas, la mayor de .871 (ítem 22) y la más baja de .371 (ítem 30). Estos resultados revelan que la variable Competencias informacionales posee una adecuada validez factorial. 
Tabla 6a. Cargas factoriales para la variable competencias informacionales

\begin{tabular}{|c|c|c|c|c|c|}
\hline No. & \multicolumn{5}{|c|}{ Factor (Componente) } \\
\hline Ítem & 1 & 2 & 3 & 4 & 5 \\
\hline 26 & .790 & & & & \\
\hline 27 & .765 & & & & \\
\hline 28 & .721 & . & & & \\
\hline 29 & .618 & & & & \\
\hline 25 & .613 & & & & \\
\hline 37 & .610 & & & & \\
\hline 50 & & .827 & & & \\
\hline 51 & & .730 & & & \\
\hline 45 & & .680 & & & \\
\hline 44 & & .667 & & & \\
\hline 40 & & .613 & & & \\
\hline 46 & & .454 & & & \\
\hline 47 & & & .752 & & \\
\hline 49 & & & 611 & & \\
\hline 24 & & & .552 & & \\
\hline 42 & & . & .539 & & \\
\hline 48. & & & .527 & & \\
\hline 39 & & & .494 & & \\
\hline 32 & & & & .800 & \\
\hline 33 & & & & .749 & \\
\hline 31 & & & & .744 & \\
\hline 34 & & & & .557 & \\
\hline 30 & & & & .371 & \\
\hline 22 & & & & & .871 \\
\hline 23 & & & & & .829 \\
\hline 41 & & & & & .487 \\
\hline
\end{tabular}

Fuente elaboración propia a través de los resultados de la rotación Varimax

Cinco fueron los factores subyacentes detectados por el análisis factorial y son: Factor 1.Capacidad para determinar la información, Factor 2.Utilización de la información, Factor 3.Evaluacion de la información, Factor 4.Acceso a la información y Factor 5.Necesidad de información.

\subsection{Variable Competencias en TIC}

El análisis de componentes principales reveló la existencia de cuatro componentes con autovalores varían de 1.21 a 7.73; el primer componente explica el mayor porcentaje de variabilidad de los datos con 21.744\%, mientras que los cuatro componentes sumados explican el $64.95 \%$ de la variabilidad (Tabla 7 ). La rotación ortogonal (Varimax) de la matriz de componentes ha agrupado los 18 ítems en cuatro factores independientes. El factor (componente) 1 agrupa 6 ítems, el factor 2 se compone de 4 ítems, el factor 3 se integra solamente de 3 ítems y, finalmente, el factor 4 posee 5 ítems.

Tabla 7. Varianza explicada en la segunda rotación para la variable competencias en TIC

\begin{tabular}{|c|c|c|c|c|c|c|c|c|c|}
\hline \multirow[t]{2}{*}{ Componente } & \multicolumn{3}{|c|}{ Autovalores iniciales } & \multicolumn{3}{|c|}{$\begin{array}{l}\text { Sumas de las saturaciones al } \\
\text { cuadrado de la extracción }\end{array}$} & \multicolumn{3}{|c|}{$\begin{array}{c}\text { Suma de las saturaciones al } \\
\text { cuadrado de la rotación }\end{array}$} \\
\hline & Total & $\begin{array}{l}\% \text { de la } \\
\text { varianza }\end{array}$ & $\begin{array}{c}\% \\
\text { acumulado }\end{array}$ & Total & $\begin{array}{c}\% \text { de la } \\
\text { varianza }\end{array}$ & $\begin{array}{c}\% \\
\text { acumulado }\end{array}$ & Total & $\begin{array}{l}\% \text { de la } \\
\text { varianza }\end{array}$ & $\begin{array}{c}\% \\
\text { acumulado }\end{array}$ \\
\hline 1 & 7.732 & 42.955 & 42.955 & 7.732 & 42.955 & 42.955 & 3.914 & 21.744 & 21.744 \\
\hline 2 & 1.441 & 8.007 & 50.962 & 1.441 & 8.007 & 50.962 & 2.756 & 15.311 & 37.055 \\
\hline 3 & 1.301 & 7.228 & 58.189 & 1.301 & 7.228 & 58.189 & 2.727 & 15.148 & 52.203 \\
\hline 4 & 1.219 & 6.770 & 64.959 & 1.219 & 6.770 & 64.959 & 2.296 & 12.756 & 64.959 \\
\hline 5 & .952 & 5.289 & 70.248 & & & & & & \\
\hline 6 & .894 & 4.969 & 75.217 & & & & & & \\
\hline
\end{tabular}

Fuente: Elaboración propia por el método de extracción: análisis de componentes principales 
En la Tabla 7a se describen las cargas factoriales de los ítems de cada factor; como se observa en su gran mayoría son altas, la mayor de .832 (ítem 52) y la más baja de .472 (ítem 55). Al igual que en la variable anteriormente mencionada los resultados revelan que la variable Competencias en TIC posee una adecuada validez factorial.

Para esta variable, cuatro fueron los factores subyacentes detectados por el análisis factorial y son: Factor 1.Profundizacion del conocimiento, Factor 2.Uso de TIC, Factor 3.Nociones básicas de TIC y, Factor 4.Generación de conocimiento.

Tabla 7a. Cargas factoriales para la variable competencias en TIC

\begin{tabular}{|c|c|c|c|c|}
\hline \multirow{2}{*}{$\begin{array}{l}\text { No. } \\
\text { ítems }\end{array}$} & \multicolumn{4}{|c|}{ Factor (Componente) } \\
\hline & 1 & 2 & 3 & 4 \\
\hline 63 & .773 & & & \\
\hline 62 & .737 & & & \\
\hline 60 & .686 & & & \\
\hline 66 & .674 & & & \\
\hline 67 & .645 & & & \\
\hline 65 & .589 & & & \\
\hline 54 & & .775 & & \\
\hline 59 & & .712 & & \\
\hline 61 & & .654 & & \\
\hline 58 & & .634 & & \\
\hline 52 & & & .832 & \\
\hline 53 & & & .805 & \\
\hline 64 & & & .694 & \\
\hline 68 & & & & 697 \\
\hline 70 & & & & 655 \\
\hline 69 & & & & 538 \\
\hline 71 & & & & 516 \\
\hline 55 & & & & 472 \\
\hline
\end{tabular}

Fuente: Elaboración propia a través de los resultados de la rotación Varimax

\subsection{Fiabilidad}

Se calculó la fiabilidad de los 44 ítems obteniendo un Alfa de Cronbach de 0.952 , lo que indica que el instrumento es aceptable. En la tabla 9 se muestra la fiabilidad de 0.930 para la variable competencias informacionales, y de 0.913 para la variable y para las competencias en TIC.

Tabla 9. Coeficiente de fiabilidad

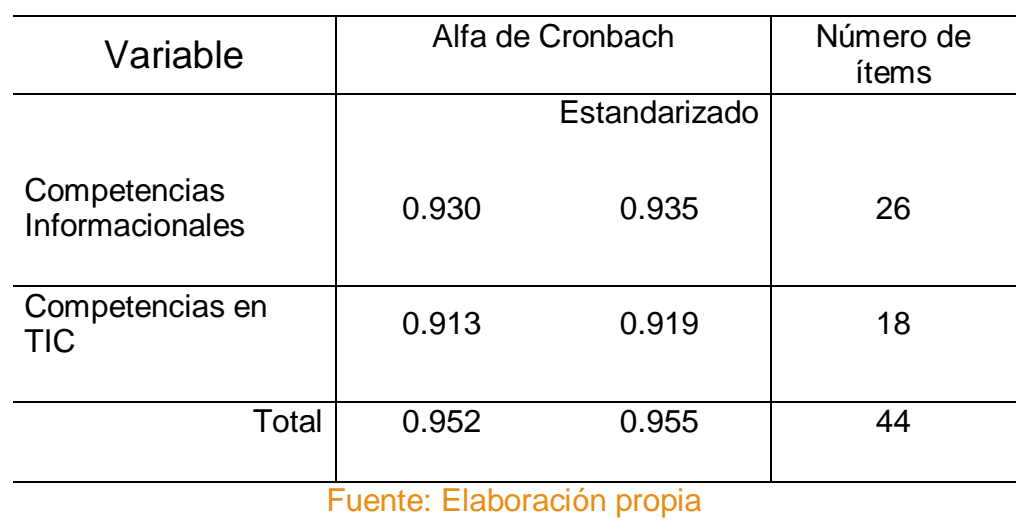




\section{Conclusiones}

Con la inclusión de tecnologías de información y comunicación en el ámbito educativo y los retos que presenta la sociedad del conocimiento, los docentes y bibliotecarios de las instituciones de educación superior están obligados a desarrollar habilidades que promuevan buenas prácticas de enseñanza-aprendizaje pues de esta manera será posible mejorar la calidad de la educación.

Por ello, con la intención de contribuir en el mejoramiento de la educación es que surge el propósito de este estudio descriptivo cuyo objetivo es validar un instrumento diseñado para medir la alfabetización informacional de docentes y bibliotecarios de las Instituciones Públicas de Educación Superior de Baja California, a partir de las variables competencias informacionales y competencias en TIC.

En general, los resultados revelan que el instrumento de medición alcanza buenos niveles de fiabilidad y validez; este último permite asegurar que lo que se pretende medir, en este caso las competencias informacionales y competencias en TIC corresponden a la realidad, y que las inferencias acerca de las competencias de las personas evaluadas por este instrumento son confiables.

En la validez de contenido se facilitó la determinación del criterio del índice cuantitativo de la validez del concepto que le corresponde a cada variable (Tristán-López, 2008), para este instrumento hubo una alta coincidencia entre los 7 jueces que validaron el instrumento. Con base en el resultado del CVR de cada ítem, fue preciso eliminar los ítems 36, 38, 43, 56, quedando el instrumento compuesto por 46 ítems.

Por lo que refiere a la validez discriminante medida a través del análisis de ítem, se encontró para la mayoría de los ítems poseen valores de los coeficientes $r$ Producto Momento aceptables $(\geq 0.3)$ en su capacidad discriminativa de acuerdo a lo que indican Millán y D’Aubeterre (2012), con excepción de los ítem 35 y 57 los cuales fueron eliminados, con ello el instrumento se redujo a 44 ítems.

En relación a la validez de constructo, ésta fue determinada mediante el análisis factorial exploratorio empleando el método de análisis de componentes principales con rotación tipo Varimax. El análisis arrojó una varianza explicada para la variable competencias informacionales de $66.766 \%$ e identificó cinco factores; mientras que para la variable competencias en TIC se detectaron solamente cuatro factores que explican el $64.959 \%$ de la variabilidad de los datos.

La consistencia interna del instrumento medida a través del alfa de Cronbach en la versión final de 44 ítems revela la adecuación del instrumento al presentar un índice de fiabilidad global de 0.952 considerándose un parámetro aceptable según Argibay (2006); los índices de consistencia interna de cada una de las variables oscilaron entre 0.930 y 0.913.

Finalmente a través del análisis realizado se concluye que el instrumento desarrollado posee las características psicométricas adecuadas para ser aplicado; sin embargo, debe considerarse que la prueba piloto se realizó empleando un muestreo por conveniencia, situación que podría tomarse como una limitante pues no existe la certeza de que toda la población ha sido considerada.

No obstante lo comentado, el aporte de esta investigación es importante por dos razones: existe un precedente sobre el cual el instrumento puede ser sometido a un proceso de validación en donde abarque a toda la población por lo cual es recomendable continuar con la aplicación del instrumento a fin de consolidar el proceso de validación aquí iniciado y, segunda, es un buen referente para realizar futuras investigaciones empíricas que identifiquen los niveles de alfabetización informacional que poseen los docentes y bibliotecarios de la educación superior, pues éstos son los principales actores del proceso enseñanza aprendizaje quienes transmitirán a los educando su saber; a través de ello, será posible establecer acciones que faciliten esa transmisión de conocimientos. 


\section{Referencias}

Aguerrondo, I. (2009) Conocimiento complejo y competencias educativas. IBE Working Paper on Curriculum. Buenos Aires, UNESCO. Recuperado de http://www.uca.edu.ar/uca/common/grupo82/files/Aguerrondo-Conocimiento-complejo-ycompetencias-educativas.pdf

American Library Association (ALA) .(2000). The Information Literacy Competency Standards for Higher Education. Recuperado de http://www.ala.org/acrl/sites/ala.org.acrl/files/content/standards/standards.pdf

Argibay, J.C. (2006). Técnicas psicométricas. Cuestiones de Validez y confiabilidad, Subjetividad y Procesos Cognitivos, 8:1533. Recuperado de:

http://dspace.uces.edu.ar:8180/jspui/bitstream/123456789/765/1/T\%C3\%A9cnicas psicom\%C3\%A9tricas.pdf

Association of College \& Research Libreries (ACRL). (2000). Normas sobre las aptitudes para el acceso y uso de la información en la enseñanza superior. Recuperado de http://www.ala.org/acrl/standards/informationliteracycompetencystandards

Avello-Martínez, R., López-Fernández, R., Cañedo-Iglesias, M., Álvarez-Acosta H., Granados-Romero, J., F., y Obando-Fraire, F. (2013). Evolución de la alfabetización digital: nuevos conceptos y nuevas alfabetizaciones. Revista electrónica Medisur, 11 (4), 450-457. Recuperado de http://www.medisur.sld.cu/index.php/medisur/article/view/2467/1291

Bonilla, V. (2013). La Convergencia de los servicios bibliotecarios telemáticos en la enseñanza universitaria E-learning. (Tesis doctoral, Universidad de Salamanca, Salamanca, España). Recuperada dehttp://gredos.usal.es/jspui/handle/10366/121339

Barriga, T. de J., Ortiz, J.L., Pérez, L.M., Sánchez, B.S. (2014). Análisis de las competencias informacionales en la comunidad académica del CICIMAR-IPN. Biblios. 56, 53-68, DOI: 10.5195/biblios.2014.180.

Barbosa-Chacón, J., Barbosa, J.C., Marciales, G.P., Peña, A (2010). Reconceptualización sobre competencias informacionales: Una experiencia en la Educación Superior. Revista de Estudios Sociales, (37), 121-142. Recuperado de http://www.scielo.org.co/scielo.php?script=sci arttext\&pid=S0123-885X2010000300007\&lng=en\&tlng=.

Campo-Arias, A. y Oviedo, H. (2008). Propiedades Psicométricas de una Escala: la Consistencia Interna. Salud Pública, 10(5), 831-839.

Carretero-Dios, H. y Pérez, C. (2005). "Normas para el desarrollo y revisión de estudios instrumentales", International Journal of Clinical and Health Psychology, 35(30), 521-551.

Carzorla, C. y Vergel, E. (diciembre 2011/febrero 2012). Propuesta de informatización para la gestión de bibliotecas mediante software libre y tecnologías web 2.0. Trabajo presentado en la III Jornada Nacional Virtual de Ciencias de la Información. Ciudad de la Habana, Cuba. Recuperado de http://www.jornada2011.sld.cu/index.php/jornada/2011/paper/viewPaper/124

Cespedes, V. (2012). Síntomas en la mujer con síndrome coronario agudo: desde las pruebas de validez. Revista Avances en Enfermería. XXX(2) 25-38. Recuperado de http://www.scielo.org.co/pdf/aven/v30n2/v30n2a02

Cortes, J. (2011). Construcción de normas para evaluar competencias informativas en los estudiantes mexicanos. (Tesis Doctoral, Universidad Nacional Autónoma de México, México, Distrito Federal) Recuperada de http://132.248.9.195/ptb2011/septiembre/0672767/0672767 A1.pdf

García, J. (2007). El desarrollo de competencias formativas en línea, en bibliotecología y ciencias de la información. Revista AIBDA. 28(1). Recuperado de http://eprints.rclis.org/10127/1/2007. Garcia-Orozco.J.F.AlBDA.28.1.competencias.pdf

García-Bellido, R. González, J. y Jornet, J.M. (2010) Material elaborado en el marco de la convocatoria de innovación de 2010 : PSS: análisis de fiabilidad. Universidad de Valencia. Recuperado de http://www.uv.es/innomide/spss/SPSS/SPSS 0801B.pdf

Gil, J.A. (2011). Técnicas e Instrumentos para la recogida de Información). Recuperado de http://es.slideshare.net/JoseLiviaSegovia/analisis-de-item

Hernández-Sampieri, R., Fernández, C. y Baptista, M.P. (2010). Metodología de la Investigación. (Quinta ed.). México: Mc Graw Hill.

Quindemil, E. (2010). Introducción de la alfabetización informacional en la especialidad de Bibliotecología y Ciencias de la Información. Acimed: Revista cubana de los profesionales de la información y la comunicación en salud. 21 (1) 98-110. Recuperado de http://dialnet.unirioja.es/servlet/articulo?codigo=3422819

Lamprea, J.A. y Gómez-Restrepo, C. (2007). Validez en la evaluación de escalas, Revista Colombiana Psiquiatría, XXXVI (2), 340-348

Lau, J., Cortes, J. (2004). (Compiladores). Normas de alfabetización informativas para el aprendizaje. México: UACJ

Lawshe, C. H. (1975). A quantitative approach to content validity. Personnel Psychology. 28 de diciembre, 563-575.

Recuperado de http://citeseerx.ist.psu.edu/viewdoc/download?doi=10.1.1.460.9380\&rep=rep1\&type=pdf

Lévy, J-P. y Varela, J. (2003). Análisis Multivariable para las Ciencias Sociales, México:Pearson Educación, SA 
López-Santana, Y. (2015) Precisiones Conceptuales de Alfabetización en Información., (pre-impreso) recuperado de http://eprints.rclis.org/25550

Medina, M. P. (2006) Los equipos multiculturales en la empresa multinacional: un modelo explicativo de sus resultados. (Tesis doctoral, Universidad de Las Palmas de Gran Canaria. Recuperado de http://www.eumed.net/tesis-doctorales/2006/mpmb/

Millán, A.C. y D’Aubeterre, M.E. (2012). Propiedades psicométricas del Maslach Burnout Inventory-GS en una muestra multiocupacional venezolana, Revista de Psicología, 30(1), 103-128

Morales, P. (2007). La fiabilidad de los test y escalas, Madrid: Universidad Pontificia Comillas

Organización de las Naciones Unidas para la Educación, la Ciencia y la Cultura (UNESCO) (2009-2014). Alfabetización Informacional. (Comunicación e Información del Programa Información para todos (PIPT) Recuperado de http://www.unesco.org/new/es/communication-and-information/intergovernmental-programmes/information-for-all-programmeifap/priorities/information-literacy/

Oviedo, H. C., \& Campo-Arias, A. (2005). Aproximación al uso del coeficiente alfa de Cronbach. Revista Colombiana de Psiquiatría, 34(4), 572-580. Recuperado de http://www.scielo.org.co/scielo.php?script=sci arttext\&pid=S0034$74502005000400009 \& \operatorname{lng}=$ en\&tlng=es.

Pérez, C. (2009). Técnicas de análisis de datos con SPSS 15. Madrid, España: Pearson Educación. [Electrónico]

Sepúlveda, F.M. (2010). Validez de los test y el análisis factorial: nociones generales. Revista Ciencia \& Trabajo. (35) 276-280. Recuperado de la base de datos: http://dialnet.unirioja.es/servlet/articulo?codigo=3218921

Sánchez, M. (2008). Las competencias desde la perspectiva informacional: apuntes introductorios a nivel terminológico y conceptual, escenarios e iniciativas. Ciência da Informação, 37(1), 107-120. Recueperado de http://www.scielo.br/scielo.php?script=sci arttext\&pid=S0100-19652008000100010\&lng=en\&tlng=es.

Tello, E. (2008). Las tecnologías de la información y comunicaciones (TIC) y la brecha digital:su impacto en la sociedad de México. Revista de Universidad y Sociedad del Conocimiento, Vol.4 (2). Recuperado de http://www.uoc.edu/rusc/4/2/dt/esp/tello.html

Tristan-López, A. (2008). Modificación al modelo de Lawshe para el dictamen cuantitativo de la validez de contenido de un instrumento objetivo. Avances en medición 6(1), 37-38.

Tuirán, R. (2011). La educación superior en México: avances, rezagos y retos. Recuperado de http://www.educacioncontracorriente.org/archivo/index.php?option=com content\&view=article\&id=22019:Ia-educacionsuperior-en-mexico-avances-rezagos-y-retos\&catid=38:tertulia-educativa\&ltemid=61

UNESCO (2008). Estándares de competencias en TIC para docentes. Recuperado de http://www.oei.es/tic/UNESCOEstandaresDocentes.pdf

UNESCO (Julio, 2009). La nueva dinámica de la Educación Superior y la Investigación para el cambio social y el desarrollo. Comunicado presentado de la Conferencia Mundial sobre la Educación - 2009 de UNESCO, Paris. Resumen recuperado de http://www.unesco.org/education/W CHE2009/comunicado es.pdf

UNESCO (2015). Comunicación e información. Alfabetización Informacional. Recuperado de http://www.unesco.org/new/es/communication-and-information/intergovernmental-programmes/information-for-all-programmeifap/priorities/information-literacy/

Uribe, A. (2010). La alfabetización informacional en Iberoamérica. Una aproximación a su pasado, presente y futuro desde el análisis de la literatura publicada y recursos web. Revista de Sistemas de Información y Documentación (IBERSID). 4, 165175. Recuperado de http://www.ibersid.eu/ojs/index.php/ibersid/article/view/3807

Uribe-Tirado, A. (2013). Lecciones aprendidas en programas de Alfabetización informacional en universidades de Iberoamérica. Propuesta de buenas prácticas. (Tesis doctoral, Universidad de Granada. España, Universidad de La Habana. Cuba). Recuperada de http://eprints.rclis.org/22416/1/TESIS\%20COMPLETA.\%20Alejandro\%20Uribe\%20Tirado.pdf

Uribe, A. (3 de octubre de 2013). El programa de ALFIN del Sistema de Bibliotecas de la Universidad de Antioquia ahora es: "cultura informacional" [mensaje de blog]. Recuperado de http://alfincolombia.blogspot.mx/2013/10/el-programa-de-alfin-delsistema-de.html 


\section{Apendice}

\section{CUESTIONARIO DESARROLLO DE HABILIDADES INFORMATIVAS}

Este cuestionario va dirigido a personal de la Institución con el propósito de solicitar información general sobre el Desarrollo de Habilidades Informativas y Uso de TIC. La información que presente es totalmente anónima y se mantendrá una absoluta confidencialidad sobre la misma. Este instrumento forma parte de un trabajo de investigación y servirá para identificar parámetros de medición de las competencias de la alfabetización informacional

Marque con una $₫$ aquella respuesta que considere conveniente de acuerdo a la siguiente escala

\begin{tabular}{|c|c|c|c|c|}
\hline Nunca & Rara vez & Ocasionalmente & Frecuentemente & Muy frecuentemente \\
\hline 1 & 2 & 3 & 4 & 5 \\
\hline
\end{tabular}

\begin{tabular}{|c|c|c|c|c|c|c|}
\hline & & 1 & 2 & 3 & 4 & 5 \\
\hline 22 & $\begin{array}{l}\text { Soy capaz de definir mis necesidades de información con relación al tema que requiero } \\
\text { investigar }\end{array}$ & & & & & \\
\hline 23 & $\begin{array}{l}\text { Sé cómo se produce, organiza y difunde la información necesaria para realizar mi } \\
\text { investigación acerca de un tema }\end{array}$ & & & & & \\
\hline 24 & $\begin{array}{l}\text { Puedo identificar el valor y las diferencias entre los recursos disponibles en una gran } \\
\text { variedad de formatos (por ej., multimedia, bases de datos, páginas web, conjunto de } \\
\text { datos, audiovisuales, libros, etc.) }\end{array}$ & & & & & \\
\hline 25 & Soy capaz de diferenciar entre fuentes de información primaria y secundaria & & & & & \\
\hline 26 & $\begin{array}{l}\text { Reconozco que el uso de información primaria y secundaria varía según las diferentes } \\
\text { disciplinas }\end{array}$ & & & & & \\
\hline 27 & $\begin{array}{l}\text { Amplio el proceso de búsqueda más allá de los recursos locales (por ej.: préstamo inter- } \\
\text { bibliotecario; uso de los recursos en otras bibliotecas de la zona; obtención de imágenes, } \\
\text { videos, texto, o sonido) }\end{array}$ & & & & & \\
\hline 28 & $\begin{array}{l}\text { Reviso la necesidad inicial de información para aclarar, reformar o refinar mi búsqueda } \\
\text { acerca del tema a investigar }\end{array}$ & & & & & \\
\hline 29 & $\begin{array}{l}\text { Se identificar palabras claves, sinónimos y términos relacionados para poder accesar a la } \\
\text { información que necesito }\end{array}$ & & & & & \\
\hline 30 & $\begin{array}{l}\text { Selecciono un vocabulario controlado específico de la disciplina o del sistema de } \\
\text { recuperación de la información para accesar a la información que necesito }\end{array}$ & & & & & \\
\hline 31 & $\begin{array}{l}\text { Construyo una estrategia de búsqueda utilizando los comandos apropiados del sistema } \\
\text { de recuperación de información elegido (por ej.: operadores Booleanos, truncamiento y } \\
\text { proximidad para los motores de búsqueda; organizadores internos, como los índices para } \\
\text { ibros). }\end{array}$ & & & & & \\
\hline 32 & $\begin{array}{l}\text { Utilizo diferentes motores de búsqueda, directorios, recursos electrónicos y meta- } \\
\text { buscadores para accesar a la información que necesito }\end{array}$ & & & & & \\
\hline 33 & $\begin{array}{l}\text { Solicito apoyo a personal especializado en el tema o servicios en línea disponibles de la } \\
\text { institución para recuperar la información necesaria (por ej.: préstamo inter-bibliotecario y } \\
\text { acceso al documento, asociaciones profesionales, oficinas institucionales de } \\
\text { investigación, recursos comunitarios, expertos y profesionales en ejercicio, consulta de } \\
\text { referencia virtual). }\end{array}$ & & & & & \\
\hline 34 & $\begin{array}{l}\text { Valoro la cantidad, calidad y relevancia de los resultados de la búsqueda para determinar } \\
\text { si necesito utilizar otro sistema de recuperación de información }\end{array}$ & & & & & \\
\hline 36 & $\begin{array}{l}\text { Conozco los diferentes estilos para referenciar autores dentro del texto (APA, AMA, } \\
\text { Chicago, Harvard, etc.) }\end{array}$ & & & & & \\
\hline 37 & Soy capaz de resumir las ideas principales de los resultados encontrados & & & & & \\
\hline 38 & Redacto los conceptos textuales encontrados con mis propias palabras & & & & & \\
\hline 39 & $\begin{array}{l}\text { Examino y comparo la información recuperada de varias fuentes para evaluar su } \\
\text { fiabilidad y validez, }\end{array}$ & & & & & \\
\hline 40 & Soy capaz de sacar conclusiones basadas en la información obtenida & & & & & \\
\hline 41 & $\begin{array}{l}\text { Indago la opinión de expertos utilizando entrevistas, correo electrónico, servidores de } \\
\text { listas de correo, etc.) para verificar la información recuperada }\end{array}$ & & & & & \\
\hline 42 & $\begin{array}{l}\text { Puedo determinar si la necesidad original de información ha sido satisfecha o si se } \\
\text { requiere información adicional. }\end{array}$ & & & & & \\
\hline 43 & $\begin{array}{l}\text { Reviso la fuente de recuperación de la información utilizada y si es necesario incluyo } \\
\text { otras fuentes de recuperación }\end{array}$ & & & & & \\
\hline 44 & $\begin{array}{l}\text { Organizo la información recuperada para la elaboración de un tema o realizar una } \\
\text { actividad (ejemplo preparación de clase, elaborar un informe, ponencia, impartición de } \\
\text { clase virtual) }\end{array}$ & & & & & \\
\hline 45 & $\begin{array}{l}\text { Integro la información obtenida, incluyendo citas y paráfrasis, de forma que apoye la } \\
\text { finalidad del tema o la actividad. }\end{array}$ & & & & & \\
\hline 46 & $\begin{array}{l}\text { Puedo elaborar una presentación, con los principales resultados encontrados para cubrir } \\
\text { las necesidades de información }\end{array}$ & & & & & \\
\hline 47 & $\begin{array}{l}\text { Comunico la información recuperada con claridad para cubrir las necesidades de } \\
\text { información }\end{array}$ & & & & & \\
\hline 48 & Comunico la información recuperada con un estilo que conviene a la audiencia & & & & & \\
\hline 49 & $\begin{array}{l}\text { Sé cómo utilizar computadora de escritorio (PC), portátiles y de mano (tipo Palm); } \\
\text { impresoras y escáneres en mis actividades laborales }\end{array}$ & & & & & \\
\hline 50 & $\begin{array}{l}\text { Manejo las funciones básicas de los procesadores de texto, hojas de cálculo, Power } \\
\text { Point para desempeñar mis actividades laborales (Microsoft Word, Open Office, MS Word } \\
\text { para Mac }\end{array}$ & & & & & \\
\hline
\end{tabular}




\begin{tabular}{|c|c|c|c|c|}
\hline Nunca & Rara vez & Ocasionalmente & Frecuentemente & Muy frecuentemente \\
\hline 1 & 2 & 3 & 4 & 5 \\
\hline
\end{tabular}

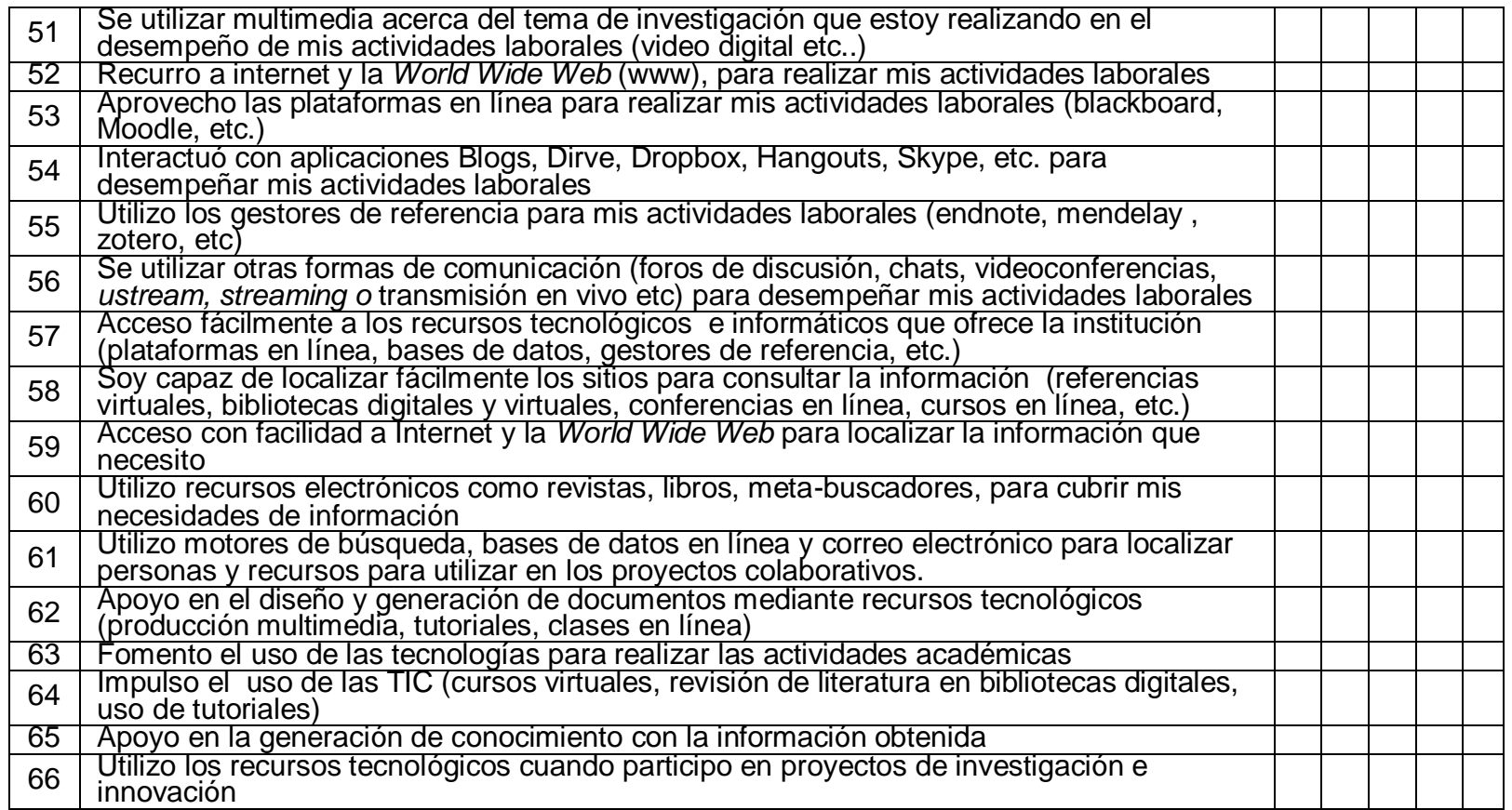




\section{Datos de los autores}

María del Carmen Toledo Sánchez

Profesora de la Facultad de Ciencias Administrativas y Sociales de la Universidad Autonoma de Baja California (UABC), alumna del Programa de Doctorado en Ciencias Administrativas de la UABC.

ctoledo@uabc.edu.mx

\section{Sonia Elizabeth Maldonado-Radillo}

Contador público. Maestría en Administración con Doctorado en Ciencias Administrativas. Es profesor de Tiempo Completo (Titular C) de la Facultad de Ciencias Administrativas y Sociales de la Universidad Autonoma de Baja California, Campus Ensenada. Actualmente dirige el Departamento de Auditoría Interna del Campus Ensenada.

sonia.maldonado@uabc.edu.mx

Recibido - Received: 2015-09-07

Aceptado - Accepted: 2015-10-27

\section{$(\mathrm{cc}) \mathrm{EY}$}

This work is licensed under a Creative Commons Attribution 4.0

United States License.

\section{ULIS D-Senter}

This journal is published by the University Library System of the University of Pittsburgh as part of its D-Scribe Digital Publishing Program and is cosponsored by the University of Pittsburgh Press. 